\title{
Accumulation of experience in a vast number of cases: enactivism as a fit framework for the study of spatial reasoning in mathematics education
}

\author{
Steven Khan · Krista Francis • Brent Davis
}

Accepted: 1 August 2014

(C) FIZ Karlsruhe 2014

\begin{abstract}
As we witness a push toward studying spatial reasoning as a principal component of mathematical competency and instruction in the twenty first century, we argue that enactivism, with its strong and explicit foci on the coupling of organism and environment, action as cognition, and sensory motor coordination provides an inclusive, expansive, apt, and fit framework. We illustrate the fit of enactivism as a theory of learning with data from an ongoing research project involving teachers and elementary-aged children's engagement in the design and assembly of motorized robots. We offer that spatial reasoning with its considerations of physical context, the dynamics of a body moving through space, sensorimotor coordination, and cognition, appears different from other conceptual competencies in mathematics. Specifically, we argue that learner engagements with diverse types of informationally 'dense' visuo-spatial interfaces (e.g., blueprints, programming icons, blocks, maps), as in the research study, afford some of the necessary experiences with/in a vast number of cases described by Varela et al. (1991) that enable the development of other mathematical competencies.
\end{abstract}

Keywords Enactivism - Sensorimotor coordination · Spatial reasoning $\cdot$ Robotics

[U]nlike the world of chessplaying, movement among objects is not a space that can be said to end neatly at some point...successfully directed

S. Khan $(\bowtie) \cdot$ K. Francis - B. Davis

Werklund School of Education, University of Calgary, 2500 University Drive, NW, Calgary, AB T2N 1N4, Canada e-mail: st.khan@ucalgary.ca movement...depends upon acquired motor-skills and the continuous use of common sense or background know-how. ...Such commonsense knowledge is difficult, perhaps impossible, to package into explicit, propositional knowledge - "knowledge that"... since it is largely a matter of readiness to hand or "knowledge how" based on the accumulation of experience in a vast number of cases. (Varela, Thompson and Rosch 1991, 147-148).

\section{Introduction}

Awareness of the importance of spatial reasoning to mathematics education is increasing. In North America, for example, the National Council of Teachers of Mathematics (NCTM) intends to increase the emphasis on spatial reasoning in the early years standards, matching the focus on number (Gojak 2012). Canadian curricula are likely to follow. In this context, it is necessary for stakeholders to critically examine what spatial skills are, how they might be envisioned in educational settings and the characteristics of tasks that might support their robust development. We present one such proposal in this paper, based on an enactivist framework.

Enactivism is viewed as a "relatively young paradigm" (Villalobos 2013, 159). Despite increasing attention in philosophy, cognitive science, and education, the "Theory of Enaction" has not yet managed to achieve significant traction in mathematics education outside of a few established social and professional researcher networks in Canada (Ernest 2006) and the UK, as evidenced by the origins of publications. We see this as an issue because the frameworks that are commonly drawn upon constrain how 
research is framed and enacted, and limit the types of sensible conclusions.

We open by inviting readers to consider a typical psychological measure used to assess one aspect of spatial reasoning_visual rotation tasks (Fig. 1) —in which participants are asked to identify the final position of a twodimensional L-shape from a series of similar gnomons that are related by rotation and/or reflection. Such tasks are believed to isolate and measure a singular dimension of spatial reasoning, viz. mental rotation, that is "the ability to rotate two- or three-dimensional stimuli in the mind" (Jansen et al. 2013, 52). The measure is also intended to be diagnostic of spatial-rotational abilities and can be framed propositionally, i.e., IF agent correctly matches gnomons, THEN capable of rotational spatial reasoning. The task boundary is well defined.

In keeping with much of the psychology-based research into mathematical cognition, such framings focus explicitly on non-visible mental processes and, frequently, on only the relationship between defined tasks and the outcomes of those invisible mental processes. In consequence, little attention is given to what might be happening elsewhere in the body. As we detail below, however, overt gestures and subtle body movements often accompany efforts to resolve this sort of mental rotation activity. For example, it is not uncommon to observe children using their hands as what appear to be proxies, angling them to mimic shapes and then turning them to give insight into the final position of a to-be-rotated object.

To illustrate, consider the actions of Eric, a 9-year-old participant in a robotics summer camp (see Fig. 2). In the video linked to the figure's caption, Eric is working with a two-dimensional L-shape in the instruction booklet and a three-dimensional L-shaped Lego ${ }^{\mathrm{TM}}$ piece.

Beginning at 1:08, (1) he looks at the partially attached L-shape on his robot-in-progress, (2) physically flips it a few times to feel its orientation, (3) moves it down to the middle rod, (4) inserts the rod and then (5) attaches the L-shape accurately (almost immediately). We hasten to add that our strategy of parsing this action of orienting-locating-assembling into a sequence of sub-actions is strictly for the purposes of highlighting its 'real-world' complexity. From there, he isolated the appropriate object from a collection of more than 80 3D shapes, many of which were differently sized Ls. He then moved back and forth between the image in the directions and the object in his hands to figure out the appropriate way to attach it to the developing robot.

In his coordinations of the Lego ${ }^{\mathrm{TM}}$ pieces through his manipulations, the boundary of the task, while constrained, is neither simple nor clearly defined. To complicate matters, this boundary shifts as the robot develops. To signal this realization of the fluidity of the task boundary, from here on we use the word $\operatorname{task}(s)$ to foreground its simultaneously singular goal and multiple operations.

While the task(s) might be seen as diagnostic, in the simple sense that a person being assessed will either be able to accomplish it or not, we claim that the task(s) is also developmental in that the person being assessed can and is learning how to accomplish the task(s) during the period of engagement. Unlike the psychological rotation task, in which no tangible feedback is provided by the test item, here, feedback is provided by the system, in that the piece either fits or does not fit. As well, Eric can make as many attempts as necessary until the piece fits.

While it might be tempting to liken elements of this sequence to the paper-based task illustrated in Fig. 1, the actual similarity to the mental rotation task seems to end with Eric's preliminary recognition (presumably involving a mental rotation) that the $2 \mathrm{D}$ visual representation in the instruction booklet refers to an L-shaped piece. The difference between the psychologically influenced task and the educative task(s) is reflected in the prevalence of summative/diagnostic abstracted assessments over developmental tasks that remain grounded in action and the body. In particular, the prevailing practice of defining curricula in terms of observable outcomes suggests a stronger alignment with the psychological task than with educative task(s).

The prominence of standardized evaluations and comparison tests further underscores the dominance of diagnostic tasks. Even though the possibility for learning exists as learners press through these cultural forms, the feedback diagnostic tasks afford little information for the teacher or the learner in their educative dimensions for both diagnosis and development. They provide some diagnosis of memorization and recall speed, but little else. In contrast to the abstract dimension of the diagnostic psychological task, the educative dimension of the task(s) emerges from interplays among physical contexts, the dynamics of a human body moving through space with other non-human bodies, and
Fig. 1 Rotation instrument (Kayhan 2005)
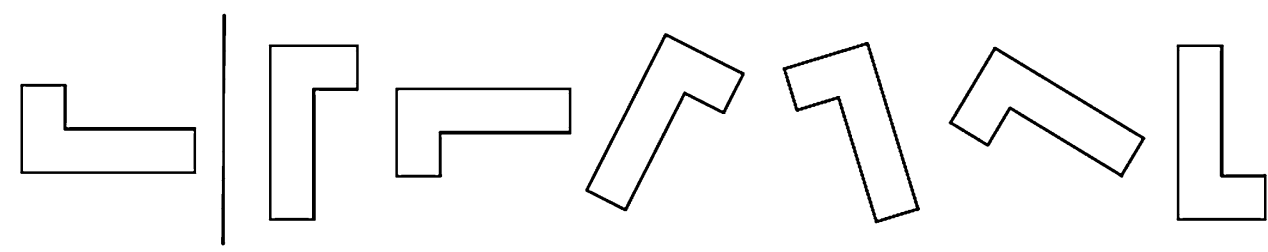


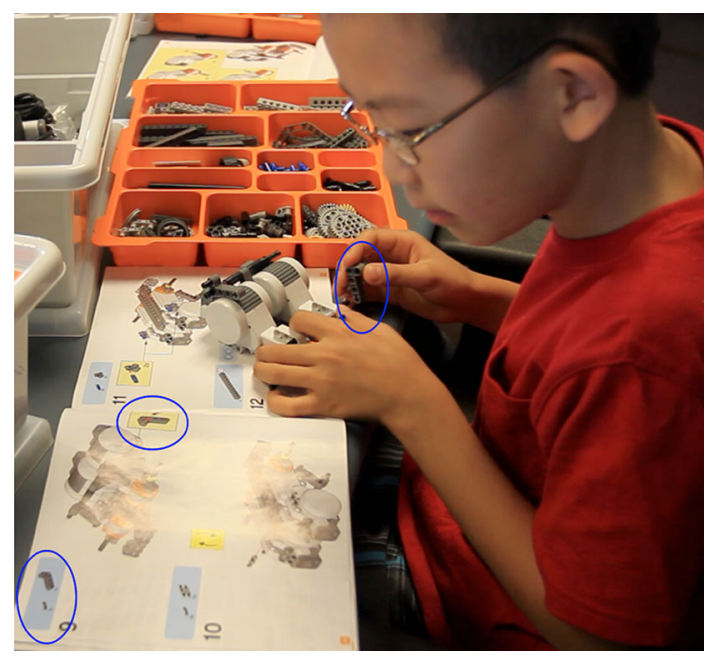

Fig. 2 Instantiations of an L-Shaped Lego piece (Video 1 Link)

cognitions and their coordinations to offer meaningful learning.

The two scenarios described above illustrate a critical distinction for us as educators and researchers. Oriented by enactivism, we regard the outcome-focused task of classical psychological research as an excessive reduction. Such tasks mask the complexity of the phenomenon by compressing multiple actions into a singular outcome; it ignores the role of the body in cognition; and it underestimates the enacted competencies of children who are engaged in real-world tasks. This critique of reductive outcomes raises the question, "What are some necessary features to which a theory of human learning must deliberately and specifically attend in order to make sense of the type of learning/engagement that we construe is taking place in the task(s) of scenario 2?" Before presenting our response, we present a concern expressed by John Dewey, regarding the influence of psychology on education-in particular, the metaphor chosen by psychologists to organize their thinking about learning. Like Dewey we believe that the founding effect of this metaphor, part of the initial conditions to which psychology was sensitive as it sought increasing scientific legitimacy in the late nineteenth and throughout the twentieth century, was to narrow and fix a limited set of interpretations and orientations to learning.

\subsection{There is something about Dewey...}

What shall we term that which is not sensation-followed-by-idea-followed-by-movement, but which is primary; which is, as it were, the psychical organism of which sensation, idea and movement are the chief organs? (Dewey 1896, p. 358)

In The Reflex Arc Concept in Psychology, Dewey (1896) claimed that the metaphorical image of the reflex arc arising from neurology was transposed into and satisfied a demand for an organizing principle for psychology. He argued that the metaphor of the reflex arc and its attendant principles of stimulus-response did not unseat previously held dualistic conceptions in which sensation and idea, or body and soul, were construed as separate, but rather repeated them. He proposed instead the concept of "sensori-motor coordination," 1 which unites, "sensory stimulus, central connections and motor responses...as divisions of labor, functioning factors, within the single concrete whole now designated the reflex arc" (p. 358). Dewey was elaborating on the well-established relationship between seeing and learning by identifying both seeing and learning as instances of sensorimotor coordination.

The metaphorical image of the reflex arc underpins schools of thought in twentieth century psychology, most notably behaviorism. This kind of thinking that the image of the reflex arc represents has led to observational protocols of stimulus and responses, uni-dimensional measurement, and "rigid distinctions between sensations, thoughts and acts" (p. 358), but it has ignored or obfuscated such considerations as feedback and subjectivity.

Our opening contrast of tasks exemplifies the focus of Dewey's critique - that is, a narrow emphasis on diagnostic measures rather than a broad conception of action that includes the organism itself and its activities. In short, Dewey drew attention to the need for a psychological framework of learning that is attentive to what he called sensori-motor coordination. Following Cummins (2013), what is necessary for the study of perception and action is a relational approach that is attentive to the limitations of "dualist mediated epistemologies" (p. 178), that is, theories of knowing in which human experience is not a priori separated from the world. We believe that enactivist theories meet Cummins' criteria as we develop in the next section.

We do not intend to suggest that Dewey's pragmatist philosophy is an earlier form of enactivism, but that the type of sensitivities and sensibilities that have come to be associated with enactivist approaches are also found in his work. While we would argue that enactivism aligns with pragmatism in powerful ways, it is not our purpose here. Enactivism, we believe, unfixes, expands and re-orients our attentions to different ways of knowing.

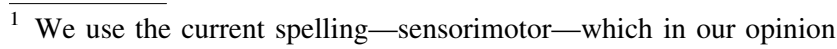
also serves to signal the juxtaposition of sensory and motor coordination.
} 


\section{Enactivism: a fit ${ }^{2}$ framework}

In this section, we address the question, 'What is enactivism?' by asking 'To what does it attend?' and 'How does it attend to it?' By way of initial, brief response, enactivism is (1) a theory of engagement (2) that is simultaneously attentive to the coupling of organisms and their environments, action as cognition, and sensorimotor coordination. (3) Attending to relevant phenomena of interest involves a methodological eclecticism (Di Jaegher and Di Paulo 2013) that is concerned with inter-agent dynamics that include feedback from the system and the organism's responses. First, we identify the specific conceptualization of enactivism from which we draw. Then we contrast enactivism with allied approaches, namely embodied cognition and constructivism.

We work from the position of Varela, Thompson and Rosch (1991) that contends that the enactivist approach comprises two principles, viz. that "(1) perception consists in perceptually guided action and (2) cognitive structures emerge from the recurrent sensorimotor patterns that enable action to be perceptually guided" (p. 173). That is to say, what an individual perceives is dependent on, but not determined by, the types of sensory stimuli that the individual's body, its physical interface with the world, encounters or seeks.

For example, with respect to perceptually guided action, Rushton (2008) states, "[t]o walk to a target you need to know where it is" (p. 36), i.e., our potential for action (walking) and goal (destination) is dependent on the perception and selection of sensory information from the physical world. Work in developmental psychology (e.g., Keen et al., 2003), which analyses infants reaching for objects, exemplify both principles of the enactivist approach we are using. Over time, repeated activity (action) establishes predictable (statistical) patterns of neural and neuromuscular activity that in turn influences the response to the stimuli sought or encountered. Humphreys et al. (2010) argue and present experimental evidence that, "our need to act upon the world not only imposes a general need for selection on our perceptual systems, but it directly mediates how selection operates. Attention is grounded in action" (p. 186). It is action then or rather potential for action that focuses attention on some features of the environment such that some aspects of sensory landscape are perceived and others are not. It is

\footnotetext{
$\overline{2}$ We use 'fit' in the bio-informational sense of suitability and adaptability of organisms to their environment or co-evolution with their ecological niche. This is not about optimization or the 'fittest' framework, though we do believe that as a fit framework enactivism includes and transcends other allied perspectives for the specific study of the phenomenon of spatial reasoning.
}

these ongoing focusing of perceptions and sensations and evaluation of goal states (feedback) that guide action.

While enactivism and embodied perspectives are related, there are crucial differences. In enactivism the external environment plays a significant role in understanding the dynamic unfolding of cognitive processes: what is in the environment is a resource for thinking, doing/knowing and being. According to Pouw, van Gog and Pass (2014), "Embodied Cognition suggests that sensorimotor information made available during previous interactions is reused for internal cognitive processing" (p. 59). Thus, while enactivism is attentive to ongoing co-constituted interaction among bodily action, cognition, and the environment, theories of embodied cognition focus on the relationship between cognition and prior action. In other words, cognition, in embodied models, is closely tied to prior sensorimotor experiences. As Pouw et al. (2014) note, "Embodied Cognition... predict[s] that learning a particular concept through sensorimotor experience is important for those concepts that draw on that information for understanding of a particular concept" (p.63).

Rather than predictions of learning a concept, enactivism is concerned with the learning in action since it is the potential for action in the world that focuses attention and drives learning. Embodied cognition is concerned with the learning from action. For example, while an embodied cognition approach would focus on Eric's improved understandings of rotation (see video 1) based on his prior engagements and for which the attention is directed toward the outcome, an enactivist approach would focus on understanding the process of learning within the environment: the attention is focused on the ongoing interaction(s).

There are also crucial differences between enactivist and constuctivist perspectives. Enactivist theories of human learning attend explicitly and deliberately to action, feedback, and discernment. They emphasize the bodily basis of meaning, distinguishing it from most accounts of constructivism, which, while not denying the body as ground and mediator of meaning, have not focused so intensely on the physicality of knowing and being. As Brown and Coles (2011) note, "[t]he enactive conception of knowledge is essentially performative" (p. 861). In contrast, constructivisms have tended to be more concerned with conceptual understanding, propositional knowledge, and webs of association (Begg, 2013; Davis, 1996) —an emphasis that perhaps inadvertently "[d]evelops rigid distinctions between sensations, thoughts and acts" (Dewey 1896, p. 358). While constructivism can also be interpreted as performative, the focus is on the outcome of actions rather than the process of interactions as in enactivism.

As frequently noted (Ernest 2006; von Glasersfeld 1995), radical constructivism is a theory of how people 
assemble ideas, with its central metaphor being an organism undergoing evolution and continually 'fitting' its cognitive schemas to the environment (Ernest 2006). Radical constructivism, however, is not a theory of how teachers might direct the assembling of ideas. It is thus relatively silent on teaching practices, such as grading or distinguishing student interpretations as right or wrong, noting only that while learning may be dependent on such teaching acts, it is not determined by them.

In contrast, enactivism is attentive to the many feedback structures in a greater-than-the-individual-learner system, more so than attention given to individual cognitive structures in radical constructivism. It is the organism as a whole, together with its environment, which co-evolves in enactivism. Thus a classroom, a school, or two learners interacting around a shared object of interest can learn. This attention to feedback structures prompts us to regard enactivism as a much more educatively minded theory than radical constructivism.

Following Begg (2013), however, it is important that enactivism not be thought of as "creating dichotomies between non-cognitive and cognitive or between experiential and academic, but as ensuring that complementary ways of knowing are all given attention and credit" (p. 93). For us, the complementary ways of knowing positions enactivism as a particularly useful frame for contrasting the two scenarios presented above-that is, the paper-based rotation task and the physically engaged robot building. Our goal in this section is to draw attention to embodied and constructivist ways of knowing in a manner that values and includes their important insights about learning while positioning enactivism as a fit framework that transcends the limitations of both perspectives.

In a recent work, Hutto (2013) argued that enactivism, with its starting assumption that mental life can be understood as embodied activity, is a good candidate for "defining and demarcating [psychology's] subject matter" (p. 174) - that is, in his terms, for "unifying psychology." Traditional perspectives, he argued, delimit psychological explanations to ones that rely on inner representational states. He noted that enactivism, in its original formulation by Varela et al. (1991), attended explicitly to organisms' varied engagements with contexts "not only of the biological kind but also of sociocultural varieties" (p. 177). The mental rotation task illustrated in Fig. 1 could be interpreted as merely a manipulation of an inner representation. Enactivism draws attention to the fact that similar neural circuits in the sensorimotor cortex are engaged across three seemingly distinct events: performing the actual physical rotation oneself, imagining the mental rotation, and observing another perform the rotation (Bergen, 2012), although the subjective experience would likely be different. This takes us to an enactivist re-framing of spatial reasoning.

\subsection{How enactivism might frame spatial reasoning}

Much debate exists within and between communities of researchers on the precise definitions and subdivisions of spatial abilities and spatial cognition (Tepylo 2013), along with their relationship to visualization, to experiences with problem solving in spatial contexts, and to the curricular form of geometry, visualizing (imagining putting together) and mental rotation (imagining how two-dimensional and three-dimensional objects appear when rotated) (Casey, Erkut, Ceder, \& Young, 2008; Linn \& Petersen, 1985); locating and recognizing objects and their paths of motion (Newcombe, 2010); and being able to infer information about three-dimensional objects with limited information (Barnett, 2013). Broadly, spatial reasoning skills can include symmetrizing, balancing, locating, orienting, decomposing/recomposing, shifting dimension, diagramming, continuity/connectedness, navigating, transformations, comparing, scaling, feeling, and visualizing (Bruce et al., 2013)

These definitions may appear divergent, but they share some key assumptions. For example, they all cast spatial reasoning as a sequential process of perceiving a separatefrom-actor object in the environment, of encoding particular features of that object (e.g., orientation), and of thinking about those features to generate motor actions and/or recognitions (e.g., of orientation or similarity). In this sense, spatial reasoning would be analogous to popular understandings of mental mathematics, as in Proulx's (2013) terms, "solving of mathematical tasks without paper and pencil or other computational/material aids" (p. 317), i.e., separating the actor from the object. Going back to our earlier discussion on Dewey's critique of the dominance of the reflex arc as a core metaphor which grounds the dominant methodologies in the psychology of learning, mental mathematics replicates and reinforces "rigid distinctions between sensations, thoughts and acts" (Dewey 1896, p. 358).

Within an enactivist frame, the implicit separation of sensorimotor action from cognitive process is inappropriate. For instance, young children's fine motor coordination and spatial reasoning have been identified as key to mathematics learning and ability. In a longitudinal study that followed 213 three- and four-year-olds through to the end of kindergarten, the ability to redraw designs or shapes was a predictor of the ability to solve mathematical problems (Grissmer, Grimm, Aiyer, Murrah, and Steele 2010). Further, Carlson, Rowe and Curby (2013) found that the fine motor skills associated with visual spatial abilities were a predictor of mathematical problem solving for 
children aged 5 through 18 years. Similarly, in an intervening pilot study, Grissmer (as cited in Sparks, 2013) studied kindergartners and first graders who, for 4 days a week over 7 months, played games that required them to copy designs and shapes, cut and paste construction paper to make chains, and build models with clay or $\mathrm{Lego}^{\mathrm{TM}}$. At the end of the study, the children demonstrated significant improvements in their mathematics skills.

These studies point to the connections of sensorimotor skills, spatial reasoning, and mathematics ability. As Cummins (2013) argued, "the reciprocity of perception and action is obscured in a perception-then-cognition-thenaction framework" (p. 183). The perspectives of Dewey (1896) and Varela et al. (1991) we described earlier point to this reciprocity, i.e., the danger of separating cognition from action. Our position is that spatial reasoning is both action and cognition.

Formal psychological definitions emphasize the effects of cognition at the expense of the very actions that accompany and co-constitute cognition. We note then a tendency in extant psychological approaches to define away a significant aspect of the phenomenon of spatial reasoning. We aim to recover some of the complexity and dynamics among the coconstituting elements by attending to the presence of the knower and the materiality of the knower in the act of spatial reasoning. Indeed, we contend that isolating such aspects of spatial reasoning as rotation, orientation, and scale, and divorcing the knower from the context of knowing, diminishes the complexity of the construct of spatial reasoning.

We thus find it more productive to describe spatial reasoning as the constrained co-occurrence of sensory flux (sensation), recognition/discrimination (perception), and situated movement of a body (or bodies) in the context of a goal-oriented situation. This tripartite set constitutes an act of spatial reasoning, rather than either invisible cognitions or actual movements alone. This is the enactivist shift, in that following Dewey (1896), "both sensation and movement lie inside, not outside, the act" (p. 359). Consistent with Maheux and Proulx (this issue), we attended to the "active, dynamic, and enacted" activity of spatial reasoning for our analysis ( $\mathrm{p} \#)$.

In the analysis below, we describe Eric's process of attaching an L-shaped object to the robot chassis. Then, we analyze Eric's actions using our definition of spatial reasoning. Then we present a case of structural coupling, which can be thought of as spatial reasoning through our enactivist framing.

\section{Analysis}

In the video-linked episode, Eric was looking for an L-shaped piece to attach to his robot-in-progress. (See

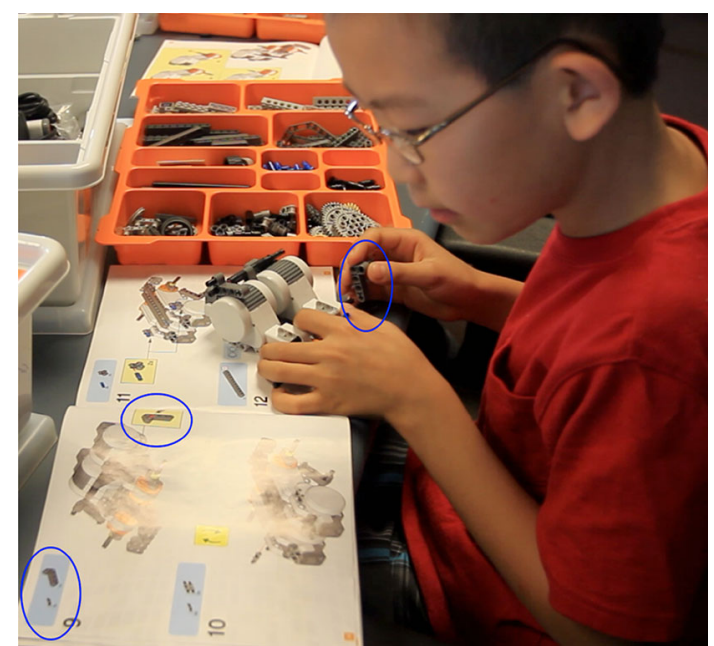

Fig. 3 Locations of L-shaped Lego piece (Video 1 Link)

Fig. 3: the piece appears in two places-and in two wayson the page of instructions.) As we aim to illustrate, this engagement is an instance of perceptually guided action that arises from perception involving visual, tactile, and sensorimotor stimuli. Before delving into our analysis, we emphasize that we make no claims about those aspects of the cognitive structures that we are unable to see, but we do talk about the recurrent sensorimotor patterns that enable action.

The required L-shaped piece was in a section of the kit to Eric's right, buried beneath another shape, and differently oriented to both illustrations in the instruction booklet. As Eric sought to find it, his gaze and hand acted in concert as he reached into the orange container (see $1^{\prime} 15^{\prime \prime}$ of Video 1). Echoing Dewey (1896), the acts of seeing and reaching were bound together. The eyes, the fingers, the wrist, and the arms all dynamically coordinate to both see and grasp the L-shape. The seeing and reaching were part of a grander coordination of recognizing and selecting the unique piece among an assortment of more than 80 distinct shapes.

When Eric's eyes, fingers, hands, wrist, and arm coordinated in the attempt to attach the L-shaped piece, there was a new whole constituted, "which makes it impossible to say which started first in the exchange of stimuli and responses" (Merleau-Ponty, 1963, as cited in Cummins, 2013, p. 183). As Eric tried to fit the L-shaped piece to the robot, what we observed was the feedback from the environment that it did not fit. We also observed him acting on the feedback in manipulating the object in new and different ways (see $1^{\prime} 28^{\prime \prime}$ of Video 1 ). He continued to try many times, until it did fit. The perception (arising from sensorimotor information) guided (and arises from) the cognition, which then guided the action. Although presented sequentially and chronologically, the co-occurrence of action, perception, and sensation does not necessarily 
happen at the exactly same time, but happens together and is co-implicated.

In Fig. 4, we draw upon our enactivist re-description of spatial reasoning as the constrained co-occurrence of sensory flux, recognition/discrimination, and situated movement. Figure 4 summarizes and represents our analysis of $18 \mathrm{~s}$ of the video clip $(1: 08-1: 26)$. We used Fig. 4 to highlight those constrained co-occurrences that we found more difficult to render in a linear, text-only format and allowed us to keep cognition(s) and action(s) together. While this representation is still insufficient for capturing the complexity of spatial reasoning from an enactivist perspective, such a framing attunes us to be attentive to more than we have perhaps been in the past.

As noted earlier, the fitting task serves both diagnostic and developmental purposes. The feedback from the system continues until the piece fits and serves both the learner and the teacher/researcher/observer.

In this section, we focused on the feedback provided to the individual from his engagement with the task and his ongoing sensorimotor adaptations to this feedback. In the next section, we shift scale to consider the interactions between two individuals around a shared focus. Shifting to this level draws our attention to the importance of simultaneously considering the variety of feedback available in a learning system. As others have noted (e.g., Brown and
Coles 2011; Mgombelo and Reid this issue), the enactivist theory of cognition does not apply solely to individual learning. Collections, and more precisely, collectives of individuals learn together with each other and with available resources in the environment.

\subsection{Structural coupling and uncoupling: the role/space} of the social from an enactivist perspective

In this sub-section we illustrate the enactivist notion of structural coupling and point to an important, but often overlooked dimension to the phenomenon in a social system (in contrast to a physical system), viz. uncoupling. The notion of structural coupling derives from a biological perspective of organisms and environments co-adapting to or co-evolving with each other. The mutual interaction of the organism and the environment causes changes and transformations in both.

Varela et al. (1991) draw on Darwin's notion of evolution to describe structural coupling of the co-adaptation of an organism and its environment, noting that the ability of an organism to un-couple from its environment is also important for the organism's survival. Being too tightly coupled to a specific environment may lead to extinction if the environment changes in even minor ways (e.g., should water levels drop substantially, a fish has fewer options for

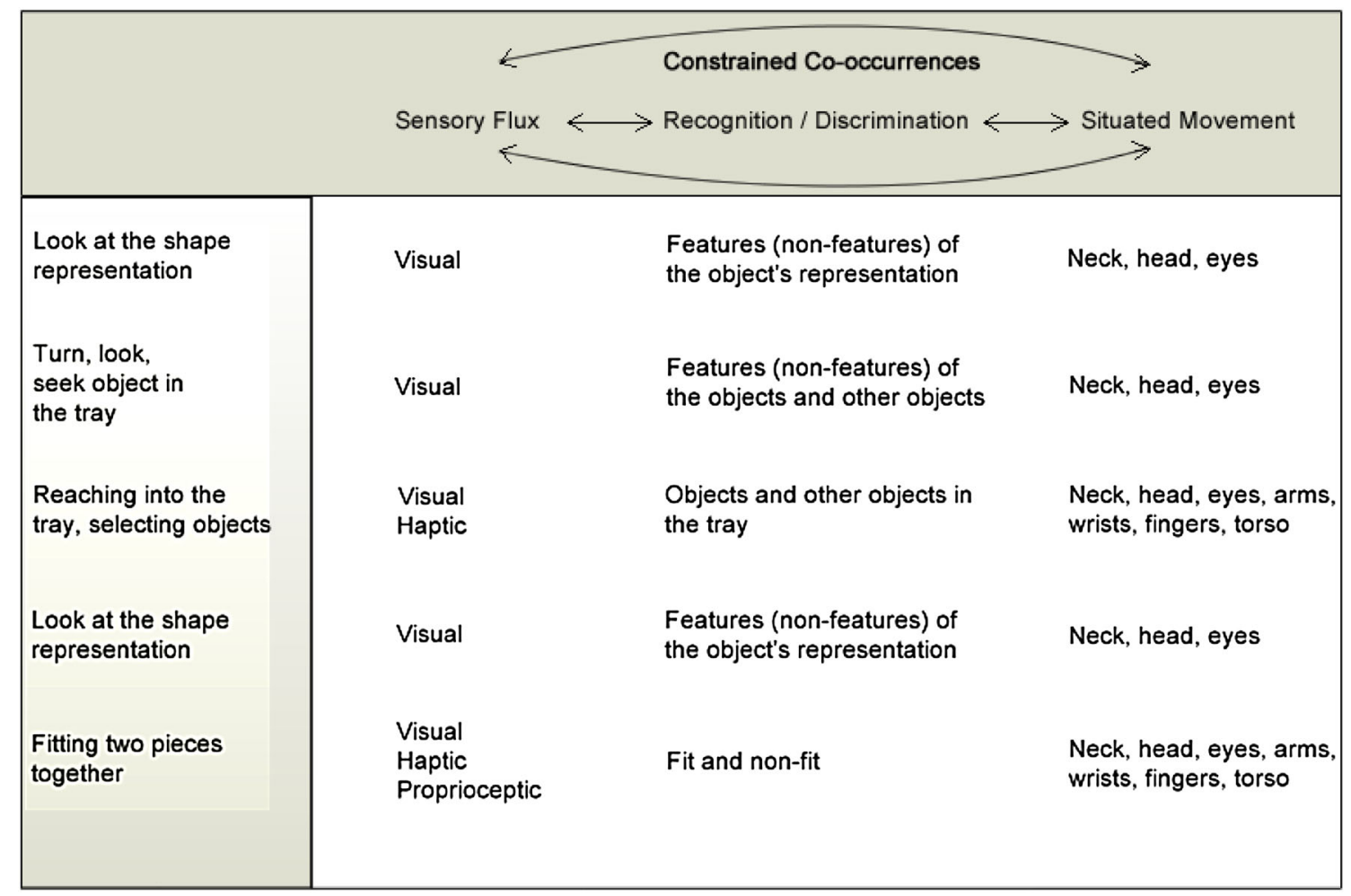

Fig. 4 Analysis summary of constrained co-occurrences 
survival than an amphibian). We draw on Varela et al. to argue that, in an educational setting, learning is dependent on both socio-cognitive coupling and uncoupling. Coupling serves as a trigger or a perturbation and the uncoupling provides opportunities for pursuing personal interest/ focus necessary for individual learning. From an educational perspective, the combined socio-cognitive coupling and uncoupling can provide opportunities for learning that enable the organism to adapt learning to other environments.

An event of socio-cognitive coupling and uncoupling is presented through the video links above (Figs. 5, 6). In these clips, while Jason is working on his own robot, Robert approaches to clarify a problem he is having with robot construction (see $0^{\prime} 40^{\prime \prime}$ of Video 2). Jason observes, analyzes Robert's current status, points, describes where the error is, and identifies the stage where the error occurred. From an enactivist perspective, this coupling of Jason and Robert triggers a number of processes.
Applying our definition above of spatial reasoning, as the constrained co-occurrence of sensory flux (sensation), recognition/discrimination (perception), and movement, Fig. 5 (and the linked Video 2 clip) shows a coupling of two children whose object of focus-the shared basis constraining the coupling-is one of their robots. The sensory flux in this coupling involves speaking, pointing, looking, touching, and holding. The recognitions of what is not right and when help is needed are the prompts for coupling. We claim that spatial reasoning is occurring as a part of the coupling in this moment. Spatial reasoning in this instance can be viewed in terms of either individual cognitive process or as interpersonal social process-or, in more educationally productive terms, as a socio-cognitive process.

On this count, we find dual-process theory (Kahneman 2011) a useful supplement to enactivism — or, at least, a helpful elaboration of Varela's (1999) development of "immediate coping." Most human action, Kahneman
Fig. 5 Coupling (Link to Video 2 clip)

Fig. 6 Uncoupling (Link to Video 2 clip)
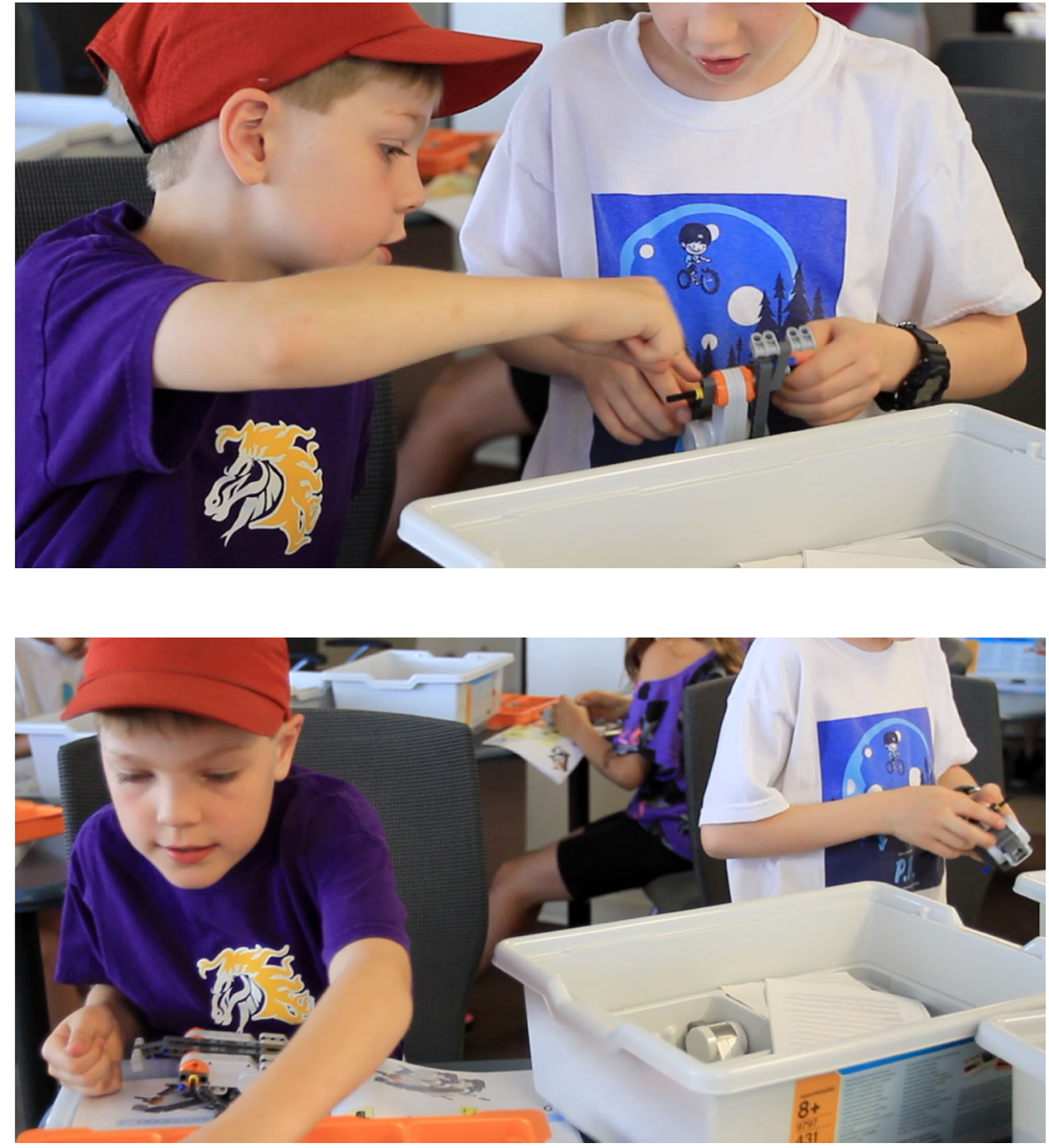
explained, is associated with a non-reflective, non-conscious sort of cognition that arises out of one's being rather than through deliberate selection. That is, most human action is enacted. Dual-process theorists posit very much the same thing in the suggestion that individual knowing arises in the co-activity of two quasi-distinct knowing systems, the Automatic (System 1) and the Reflective (System 2). System 1 is quick and intuitive, rooted in memory and rehearsed experience, more given to analogy than to logic, and usually accurate in its reads and responses. System 2 is slow and deliberate, based in conscious thought, and concerned with novelty or perceived incoherences. It tends to be much more logical than System 1 , and more prone to misreadings and unfitting responses.

Accumulating sufficient experiences in a diverse number of cases results in shifts from System 2 to System 1 . That is to say, certain aspects of cognition and action become more automatic and less consciously reflective. Most of the time, the Reflective System 2 defers to the smooth and expert functioning of Automatic System 1. It is only when a threshold of unfamiliarity or confusion-a perturbation, in the vocabulary of enactivism-is met that System 2 is triggered into action.

We see both systems in play for both actors in the clips above. To discern the coupling and uncoupling of Jason's and Robert's Systems 1, we find it helpful to mute the sound and focus on the fluid choreography of their mutually specifying actions. These actions are smooth, precisely timed, exquisitely coordinated, and astonishingly free of excess motion. Such are the hallmarks of automatized action, which, to our observation, are appropriately characterized as embodied or enacted knowings.

Of course, we must be careful not to understate the roles and couplings of the actors' Systems 2 in this episode. After all, the event was triggered by Robert's conscious recognition of a difficulty. That is, in terms of dual-process theory, Robert encountered an instance of insufficient and/ or inadequately integrated experiences to evoke a routinized response in a novel situation. Lacking that, another of his automatized responses appears: he calls on a likely-toknow and proximate other. Once System 2 is oriented to this course of action, System 1 appears to take over again, as suggested by the fluidity of the actions and articulations.

Jason's response is similarly interesting. Its immediacy indicates that the solution he offers to Robert was drawn from his repertoire of rehearsed actions. We might say that Jason draws on his expertise, based on his accumulation of experiences in this domain. While we do not have evidence of what Varela (1999) called "deliberate analysis" given the age of the learner, we wish to suggest that the interaction in the video shows "intelligent awareness" which, as Brown and Coles (2011) describe, entails "both acting spontaneously and able to analyse afterwards" (p. 862).
Post-event analysis, we believe, is demonstrable in the moment when Robert returns to discuss the eventual solution that he found based on the suggestion offered by Jason.

More interesting to us is the seamless sequence of Jason's couplings and uncouplings, starting with a cognitive uncoupling from his own work, a socio-cognitive coupling with Robert, a socio-cognitive uncoupling from Robert, and a cognitive recoupling with the original task. These subevents occurred in just seconds, at a speed that exceeded the capability of System 2. They were examples perhaps of what Varela describes as immediate coping (1999).

Turning back to Robert, the instant of social uncoupling afforded him an opportunity to process what Jason disclosed (see $0^{\prime} 56^{\prime \prime}$ of Video 2). He then returns to Jason to explain what the problem was (see $1^{\prime} 05^{\prime \prime}$ of Video 2). The temporary uncoupling provides the time and space for individual reflection, which within a social context that supports accumulating experiences in a vast number of cases, serves as an occasion for sharing learning.

To be clear, we are still talking about spatial reasoning here, i.e., constrained co-occurrence of sensory flux (sensation), recognition/discrimination (perception), and situated movement of bodies in the context of a goal-oriented situation. Our point is that spatial reasoning competence is not a solitary achievement, but one that arises in the main amid such socio-cognitive couplings and uncouplings. Of course, the same might also be said of other mathematical competencies. However, the particular advantage of the topic of spatial reasoning is that understandings are typically much more available to observation. We can, literally, see Robert's and Jason's understandings in their actions.

Moreover, and somewhat provocatively, when we watch an accelerated version of the more complete recording of the extended engagement from which this episode is extracted, we observe a distinct pattern of structured interactivity in which agents pull together and move apart in a rhythmic pulse as they structurally couple and uncouple. In our enactivist framing, we would be curious about those moments of coming together and those moving apart, the pulse of complexity, as occasions for accumulating experience in a vast number of cases for individuals and for the collective.

\section{Conclusions}

We set out to show that enactivism is a fit framework for the study of spatial reasoning. Enactivism permits us to observe and define the processes of spatial reasoning in a manner that can inform structuring occasions for its development. As we prepare this paper we note an 
emergent emphasis on visualization (Rivera Steinbring and Arcavi 2014) with links to work on mental rotation. We would argue that a renewed study of visualization in mathematics education must necessarily attend to the significant role of the body in space with other bodies. As Presmeg (2014) notes, questions about "[h]ow are touch and sight related in various relevant contexts?" (p. 156) remain unanswered even in light of the important work being done in embodied cognition. She suggests that "conceptual frameworks for research that links visual and haptic modalities are still in need of development" (p. 56). We agree and suggest that enactivism provides a 'fit' framework for theorizing that includes and transcends a focus on haptics.

\subsection{Implications}

To understand mentality, however complex and sophisticated it may be, it is necessary to start by appreciating how living beings dynamically interact with their environments, both shaping and being shaped by those encounters; ultimately there is no prospect of understanding minds without reference to ongoing interactions between organisms and their environments. (Hutto 2013, p. 176)

We note that constructivisms, as adopted and adapted within the field of mathematics education in the twentieth and early twenty first centuries, have been mainly concerned with conceptual understanding of numerical and algebraic concepts. While some enactivist-aligned contributions have highlighted the importance of taking into account the body in efforts to make sense of these areas of mathematical competence (e.g., Lakoff \& Núñez 2000), it is telling that relatively little of the research into arithmetic and algebraic competence delves deeply into the bodily basis of meaning.

In contrast, with the emergent recognition that spatial reasoning is a core element of mathematics competence, it is apparent that theories of learning that are principally focused on the evolutions of personal conceptual coherence are inadequate. Spatial reasoning is much more obviously and directly anchored to one's experiences, situatedness, and intentions - in brief, one's enactments. Returning to our title, what counts as sufficiently vast for individual learners will not be the same for others.

When we consider the longstanding tensions between knower-centered constructivisms and socio-cultural accounts of learning and knowing, we are even more compelled toward an enactivist frame. Intricate dances of cognitive and social coupling and uncoupling complexify perspectives that privilege one or another domain of (inter)action such as social constructivism or cognitivism.
Our enactivist framing above as the constrained cooccurrence of sensory flux (sensation), recognition/discrimination (perception), and movement of a body, presents one opportunity for the field to re-consider both the phenomenon of interest and the way of studying it. However, we conclude that the phenomenon for which the concept/signifier 'spatial reasoning' is used as a descriptor is a complex one. Enactivist perspectives, we believe, offer fit frameworks for interpreting and investigating what it means to weave one's embodied and knowing self through the world.

Acknowledgments This research was funded by the Imperial Oil Science Engineering and Technology (IOSTEM) Education Initiative. We thank the teachers and children who participated in the IOSTEM Academy. We are also grateful to Michael Poscente for designing and coaching the Lego ${ }^{\mathrm{TM}}$ robotics task and Dr. Shalini Khan for editorial and proofreading assistance.

\section{References}

Barnett, T. (2013). What is spatial ability? wiseGEEK. Retrieved September 26, 2013, from http://www.wisegeek.org/what-isspatial-ability.htm.

Begg, A. (2013). Interpreting enactivism for learning and teaching. Education Sciences and Society, 4(1). Retrieved January 15, 2014 from http://riviste.unimc.it/index.php/es_s/article/view/ 699.

Bergen, B. (2012). Louder than Words: The new science of how the mind makes meaning. NY: Basic Books.

Brown, L., \& Coles, A. (2011). Developing expertise: how enactivism reframes mathematics teacher development. ZDM-The International Journal on Mathematics Education, 43(6-7), 861-873. doi:10.1007/s11858-011-0343-4.

Bruce, C. D., Moss, J., Sinclair, N., Whiteley, W., Okamoto, Y., McGarvey, L., et al. (2013). Early years spatial reasoning: Learning, teaching and research implications. Workshop Presented at the NCTM research presession: Linking research and practice, Denver, CO.

Carlson, A. G., Rowe, E., \& Curby, T. W. (2013). Disentangling fine motor skills' relations to academic achievement: the relative contributions of visual-spatial integration and visual-motor coordination. The Journal of Genetic Psychology, 174(5), 514-533. doi:10.1080/00221325.2012.717122.

Casey, B., Erkut, S., Ceder, I., \& Young, J. (2008). Use of a storytelling context to improve girls' and boys' geometry skills in kindergarten. Journal of Applied Developmental Psychology, $29,29-48$.

Cummins, F. (2013). Towards an enactive account of action: speaking and joint speaking as exemplary domains. Adaptive Behavior, 21(3), 178-186. doi:10.1177/1059712313483144.

Davis, B. (1996). Teaching mathematics: toward a sound alternative. New York: Garland.

Dewey, J. (1896). The reflex arc concept in psychology. Psychological Review, 3(4), 357-466.

Di Jaegher, H., \& Di Paulo, E. (2013). Enactivism is not interactionism. Frontiers in Human Neuroscience, 6(345), 1-2. doi:10. 3389/fnhum.2012.00345.

Ernest, P. (2006). Reflections on theories of learning. ZDM-The International Journal on Mathematics Education, 38(1), 3-7. 
Gojak, L. (2012). Helping our students become mathematical thinkers. Presidential Address presented at the NCTM 2012 Annual Meeting, Philadelphia. Retrieved February 12, 2014, from http://www.nctm.org/conferences/content.aspx?id=33201.

Grissmer, D., Grimm, K. J., Aiyer, S. M., Murrah, W. M., \& Steele, J. S. (2010). Fine motor skills and early comprehension of the world: two new school readiness indicators. Developmental Psychology, 46(5), 1008-1017. doi:10.1037/a0020104.

Humphreys, G. W., Yoon, E. Y., Kumar, S., Lestou, V., Kitadono, K., Roberts, K. L., et al. (2010). The interaction of attention and action: from seeing action to acting on perception. British Journal of Psychology, 101(2), 185-206. doi:10.1348/ $000712609 X 458927$.

Hutto, D. D. (2013). Psychology unified: from folk psychology to radical enactivism. Review of General Psychology, 17(2), 174-178. doi:10.1037/a0032930.

Jansen, P., Schmelter, A., Quaiser-Pohl, C., Neuberger, S., \& Heil, M. (2013). Mental rotation performance in primary school age children: are there gender differences in chronometric tests? Cognitive Development, 28(1), 51-62. doi:10.1016/j.cogdev. 2012.08.005

Kahneman, D. (2011). Thinking, Fast and Slow. NY: Farrar, Strauss $\&$ Giroux.

Kayhan, E. B. (2005). Investigation of high school students' spatial ability. Middle East Technical University, Turkey. Retrieved September 25, 2013, from https://etd.lib.metu.edu.tr/upload/ 12605771/index.pdf.

Keen, R., Carrico, R. L., Sylvia, M. R., \& Berthier, N. E. (2003). How infants use perceptual information to guide action. Developmental Science, 6(2), 221-231. doi:10.1111/1467-7687.00274.

Lakoff, G., \& Núñez, R. E. (2000). Where mathematics comes from: how the embodied mind brings mathematics into being. New York: Basic Books.

Linn, M. C., \& Petersen, A. C. (1985). Emergence and characterization of sex differences in spatial ability: a meta-analysis. Child Development, 56(6), 1479-1498. doi:10.2307/1130467.

Maheux, J. F., \& Proulx, J. (2015). Doinglmathematics: Analysing data with/in an enactivist-inspired approach. ZDM-The International Journal on Mathematics Education, 47(2).
Mgombelo, J., \& Reid, D. A. (2015). Key concepts in enactivist theory and methodology. ZDM-The International Journal on Mathematics Education, 47(2).

Newcombe, N. S. (2010). Picture this: increasing math and science learning by improving spatial thinking. American Educator, 34(2), 29-35.

Pouw, W. T. J. L., van Gog, T., \& Paas, F. (2014). An embedded and embodied cognition review of instructional manipulatives. Education Psychology Review, 26, 51-72. doi:10.1007/s10648014-9255-5.

Presmeg, N. (2014). Contemplating visualisation as an epistemological learning tool in mathematics. ZDM-The International Journal on Mathematics Education, 46(1), 151-157. doi:10. 1007/s11858-013-0561-z.

Proulx, J. (2013). Mental mathematics, emergence of strategies, and the enactivist theory of cognition. Educational Studies in Mathematics, 84(3), 309-328. doi:10.1007/s10649-013-9480-8.

Rivera, F. D., Steinbring, H., \& Arcavi, A. (2014). Visualisation as an epistemological learning tool: an introduction. ZDM-The International Journal on Mathematics Education, 46(1), 1-2. doi:10.1007/s11858-013-0552-0.

Rushton, S. K. (2008). Perceptually guided action: a step in the right direction. Current Biology, 18(1), R36-R37. doi:10.1016/j.cub. 2007.10.064.

Sparks, S. D. (2013). Children's spatial skills seen as key to math learning. Education Week, 32(31). Retrieved January 8, 2014, from http://www.edweek.org/ew/articles/2013/05/15/31learning. h32.html.

Tepylo, D. (2013). Spatial reasoning: considerations for mathematics educators. Toronto: University of Toronto.

Varela, F. J. (1999). Ethical know-how: Action, wisdom, and cognition. Stanford University Press.

Varela, F. J., Thompson, E., \& Rosch, E. (1991). The embodied mind: cognitive science and human experience. Cambridge: MIT Press.

Villalobos, M. (2013). Enactive cognitive science: revisionism or revolution? Adaptive Behaviour, 21(3), 159-167.

von Glasersfeld, E. (1995). Radical constructivism: a way of knowing and learning. Washington, D.C.: Falmer Press. 